\title{
Conexões Brasil-China: a migração chinesa no centro de São Paulo
}

\author{
Brazil-China Connections: the chinese \\ migration in downtown São Paulo
}

Carlos Freire da Silva

\begin{abstract}
Resumo
A partir da abertura econômica da China em 1979, vem se constituindo uma dinâmica socioeconômica que liga centros atacadistas entre China e Brasil através de fluxos comerciais e de mobilidades migratórias. São rotas que abastecem mercados populares e envolvem uma constante circulação de pessoas, sobretudo, entre São Paulo, Guangzhou e Yiwu. Este artigo discute o estabelecimento dos migrantes chineses no comércio popular do centro de São Paulo, através das galerias e da "feira da madrugada" nas regiões da 25 de Março e do Brás, atualmente o maior centro distribuidor do País de mercadorias importadas diretamente da China. Trata-se não apenas de localizar um processo migratório no espaço, mas de como este afeta a reestruturação das localidades ao promover a articulação de dinâmicas socioeconômicas transnacionais.
\end{abstract}

Palavras-chave: migração chinesa; rotas comerciais; Brasil-China.

\begin{abstract}
From the economic opening of China in 1979 until these days, a socioeconomic dynamics has been forming, linking wholesale centers between China and Brazil through trade flows and migratory mobilities. These are routes that supply popular markets and involve a constant movement of people, especially between São Paulo and the cities of Guangzhou and Yiwu. This article discusses the establishment of Chinese migrants in the popular trade of downtown São Paulo, through galleries and the "dawn market" located in the neighborhood of Brás and on a street called 25 de março - currently, the country's largest distributor of goods imported directly from China. It is not only a question of locating a migratory process in space, but of how it affects the restructuring of places by promoting the articulation of transnational socioeconomic dynamics.
\end{abstract}

Keywords: Chinese migration; trade routes; Brazil-China. 
A diáspora chinesa ocupa lugar de destaque na ordem global das migrações, sendo a China a principal provedora de migrantes no mundo ${ }^{1}$ distribuídos por mais de 150 países (Wei, 2010). A migração chinesa para o exterior vem de longa data, com um incremento significativo a partir de meados do século XIX, depois da primeira guerra do Ópio (1839 a 1842) através do sistema coolie. No período entre a revolução comunista e a abertura econômica, em que a saída da China continental era restrita, a migração para o exterior ocorria basicamente a partir de Hong Kong e Taiwan. Depois da abertura e da viabilidade legal para migração dada pelo governo central para qualquer pessoa que conseguisse um visto para o país de destino, os incentivos econômicos dos governos locais tiveram participação ativa na promoção da migração, principalmente nas províncias de Guangdong, Zhejiang e Fujian (ibid., pp. 33-34).

Os países do sudeste asiático foram os principais receptores da diáspora chinesa, seguidos pelos Estados Unidos e pelo Canadá, na América do Norte, e pela Itália, Inglaterra, Espanha e França, na Europa. Apesar de ter mais de 200 anos de história, o crescimento recente da migração chinesa para o Brasil acompanha uma reorientação de vetores que faz com que esse fluxo migratório tenho crescido ultimamente entre a América Latina e África, estando o Brasil situado atrás apenas do Peru como principal concentração de chineses em países sul-americanos (Stenberg, 2012). 0 redirecionamento dos fluxos migratórios traz elementos importantes para pensarmos sobre dinâmicas transnacionais que não se resumem apenas as orientações globais dos mercados financeiros. Podemos tomar a migração chinesa como vetor analítico para se pensar a dinâmica das relações entre Brasil e China.

A mobilidade de chineses para o País constitui um dos principais fluxos migratórios das últimas décadas. Tomando como indicadores alguns dados do Ministério da Justiça sobre estrangeiros que procuraram regularizar sua situação no País durante a última anistia em 2009, eles constituíram o segundo maior grupo por nacionalidade com 5,5 mil inscritos, atrás apenas dos bolivianos com 17 mil inscritos. $^{2}$ Nas tabulações dos microdados da amostra do Censo de 2010, a estimativa seria de 12.554 pessoas nascidas na China vivendo no estado de São Paulo, das quais 63,5\% estariam na cidade de São Paulo; e, para todo o Brasil, a estimativa seria de 23.156 pessoas (Freire da Silva, 2014). Porém, reconhecidamente os dados do censo tendem a subdimensionar certas dinâmicas migratórias. Na sessão da Assembleia Legislativa do Estado de São Paulo em homenagem aos 200 anos da migração chinesa para o Brasil, registrada no Diário Oficial de 23 de maio de 2012, o consulado Chinês em São Paulo e a Associação Chinesa do Brasil estimavam em 250 mil o número de chineses e de seus descendentes no Brasil, 180 mil morando em São Paulo. ${ }^{3}$ Embora a migração em si não seja propriamente uma novidade, as informações dos microdados da amostra do Censo de 2010 indicam que mais de $60 \%$ dos chineses residentes na RMSP teriam se estabelecido no País depois de 1995 e ao longo da década de 2000 (ibid., p. 142).

De certo modo, o crescimento da migração chinesa para o Brasil acompanha o próprio avanço das relações socioeconômicas com a China. Na cidade de São Paulo, os migrantes chineses e seus descendentes estão presentes 
em diversas áreas de atuação, como médicos, advogados, professores universitários, profissionais liberais em geral, donos de mercadinhos e restaurantes, entre outros, também profissionais e técnicos ligados a empresas chinesas que vieram investir no País nos últimos anos. No entanto, chama a atenção a grande concentração de migrantes chineses nas galerias comerciais da região central da cidade, principalmente nas regiões da rua 25 de Março e do Brás, comercializando mercadorias importadas diretamente de seu país de origem. 0 circuito de mercadorias made in China, distribuídas no comércio popular, não ocorre em um universo paralelo ao das grandes empresas que procuram, na China, menores custos de produção. A circulação de pessoas é parte constitutiva da construção das relações comerciais entre os dois países e, muito concretamente, estabelece uma ligação entre mercados do centro de São Paulo e das cidades de Guangzhou e Yiwu, no sul da China.

Este artigo reflete pesquisa desenvolvida entre 2010 e 2014 durante o doutorado (ibid.) e sua continuação em um pós-doutorado em curso desde o final de 2015. A pesquisa consistiu em observação em campo junto à região da 25 de Março e do Brás, nas galerias comerciais e na feira da madrugada, em entrevistas com comerciantes chineses e representantes de associações chinesas, além de fontes secundárias como os canais de notícias dos migrantes no wechat (aplicativo muito popular entre os chineses usado como rede social e para trocas de mensagem, entre outras funções). Também foram realizados dois períodos de pesquisa na China (dois meses em 2013, quatro meses em 2016), sobretudo em Guangzhou e Yiwu. Em termos teórico-metodológicos, procuramos refletir sobre essa dinâmica migratória transnacional na escala da cidade, pensando em seu impacto urbano e nas dinâmicas transnacionais que ela articula. Trata-se de pensar a incorporação de processos migratórios transnacionais em seu impacto na reestruturação das localidades (Glick-Schiller e Çaglar, 2008). Procuramos levar em consideração as críticas ao "nacionalismo metodológico" em estudos de migração transnacional, que consistiria em uma tendência a abordar processos sociais e históricos como se eles estivessem contidos dentro de Estados nacionais (ibid.); e também buscando se distanciar da abordagem "étnica" sobre a mobilidade transnacional.

Desse modo, não se trata de uma discussão sobre a migração chinesa para o Brasil de modo geral. Também não se trata de uma discussão sobre "nicho étnico" ou "empreendedorismo étnico" que procure explicar pela origem nacional ou por uma identidade étnica que coincida com a nacionalidade, o tipo de engajamento que os migrantes terão nas atividades em que eles se concentram. Trata-se aqui antes de analisar um processo específico da migração chinesa e o seu impacto no desenvolvimento dos mercados populares no centro de São Paulo, bem como a dinâmica transnacional que se estabelece com alguns mercados em cidades no sul da China. 0 desenvolvimento e as transformações dos mercados populares da 25 de março e do Brás, em conjunto com a influência da migração chinesa na produção e renovação desses espaços, revelam-nos uma dimensão importante da relação entre os dois países, mostrando conexões com alguns espaços específicos na China que são estruturantes para esse tipo de comércio transnacional. 


\section{Transformações do espaço urbano}

Nos arredores da rua 25 de Março e av. Senador Queiros, distrito da Sé na região central de São Paulo, anúncios em mandarim são marcas recorrentes e cotidianas no espaço urbano. Trata-se de referências aos vários serviços direcionados aos migrantes chineses que moram e, principalmente, trabalham na região. Há creches para as crianças permanecerem durante a jornada de trabalho dos pais e também uma escola bilíngue que passou por uma reorientação pedagógica para receber as crianças em idade escolar. No caso, o Colégio São Bento, um dos mais tradicionais colégios particulares da cidade, onde atualmente mais de metade de seus alunos são filhos de chineses. 0 colégio é ligado ao Mosteiro São Bento e está localizado bem próximo à rua 25 de Março. Era um colégio voltado à elite paulistana, mas que se viu preterido à medida que esta se distanciava do centro. Vivia uma crise financeira até o ano de 2007, com um número muito pequeno de alunos e com a ameaça de encerrar suas atividades. Isso mudou depois de um acordo através da Associação dos Chineses do Brasil e das adequações pedagógicas para receber os filhos dos migrantes chineses. 0 colégio oferece ainda aulas de português para adultos no período noturno e de mandarim para o público em geral. Alguns empresários chineses da região também fizeram doações financeiras ao colégio, que permitiram amplas reformas em sua estrutura.

0 caso do Colégio São Bento dá uma dimensão qualitativa da influência chinesa nessa região central, mas também há mercadinhos de produtos típicos da China importados para o suprimento diário, uma feirinha ocasional de verduras e legumes apreciados na culinária chinesa e vendidos na calçada da rua Florêncio de Abreu por chineses, os restaurantes de culinária chinesa frequentados apenas por chineses e os serviços de marmita que distribuem comida nos pontos de comércio. Além de outros serviços, mais discretos, como uma agência de viagens que vende passagens da China Airlines, escritório de contabilidade voltados a auxiliar os comerciantes com as burocracias de suas empresas na cidade e, um pouco mais distante, uma agência de transferências monetárias da Western Union, com letreiros em chinês.

Tais serviços em larga medida gravitam em torno da atividade comercial das galerias da região e da importância que exercem no desenvolvimento recente desse fluxo migratório para a cidade de São Paulo. Entre lojistas e vendedores, encontram-se, na maioria, migrantes chineses vendendo os mais diversos produtos importados de seu país de origem. A atividade comercial nas galerias é acompanhada por escritórios de importação e exportação e por inúmeros depósitos que chegam a ocupar prédios inteiros. A partir das galerias da área central, principalmente no eixo entre a 25 de Março e o Brás, os chineses fornecem no atacado e no varejo os produtos importados diretamente da China que circulam no comércio popular, seja entre vendedores ambulantes, seja entre lojinhas nas periferias e no comércio de modo geral. Por sua vez, através das excursões de sacoleiros para a região central, as mercadorias são dispersas para inúmeras cidades espaIhadas pelo País. Alguns outros comerciantes chineses situados em centros de comércio de outros estados também têm a região central de 
São Paulo como lugar de abastecimento, principalmente no Rio de Janeiro, Belo Horizonte e Pernambuco. De modo que a atividade dessas galerias exerce centralidade na dinâmica do fornecimento de mercadorias que circulam nos mercados populares para muito além dos limites da cidade.

0 modelo de comércio em galerias multiplicou-se no período entre 2000 e 2014, mesmo transformando os espaços tradicionais de comércio. Também conhecido como mini shopping ou shopping popular, nele o espaço é subdividido em uma série de pequenos boxes de não mais do que $4 \mathrm{~m}^{2}$, em alguns casos, quando o espaço é mais valorizado, um ponto de comércio é apenas um pequeno espaço em um balcão compartilhado com outros lojistas. Os boxes são sublocados para um grande número de comerciantes que investem menos do que o valor do aluguel de uma loja tradicional, mas muito mais pelo custo de cada metro quadrado. Diante disso, o comércio tradicional vai cedendo espaço para as galerias, é mais vantajoso para seus proprietários sublocar o espaço em vários pequenos boxes do que ocupá-lo com o comércio tradicional. Essa lógica de subdivisão do espaço e a dinâmica comercial da região são motivos para a extrema valorização do custo do aluguel do metro quadrado na região da 25 de Março e do Brás, que chega a ser muito mais caro do que os espaços de comércio de luxo na cidade. Também é a causa da multiplicação dos pontos de comércio na região, são milhares os pequenos boxes que se espalham entre prédios e galpões da 25 de Março e do Brás, incluindo a feira da madrugada.

A mais famosa dessas galerias é a Galeria Pagé, em funcionamento desde o início da década de 1960 em um prédio de duas torres; uma ocupada por escritórios e a outra por oito andares de lojas. Em princípio, eram lojas padrão e só posteriormente foram subdivididas em vários pontos de comércio. Nos anos 1990, surgiram outras galerias grandes como o Shopping 25 de Março e o Shopping Mundo Oriental, mas foi, no correr dos anos 2000, que esse modelo de comércio se alastrou para outros centros de comércio, principalmente no Brás e na Santa Ifigênia, mas também na av. Paulista, Liberdade, Largo 13, entre outras áreas importantes de comércio na cidade. No Brás, as galerias proliferaram a partir dos anos 2000, sendo o Shopping 25 de Março-Brás um dos pioneiros, marcando a expansão de um circuito comercial mais típico da região da rua 25 de Março em direção ao polo das confecções.

A presença chinesa no comércio acompanhou em larga medida a difusão desse formato de comércio de galeria. Por certo que a migração chinesa em São Paulo não se reduz ao comércio nas galerias, com uma origem anterior ao período analisado e se inserindo em outras regiões e setores de atividade. Entretanto essas atividades comerciais deram impulso à mobilidade migratória de chineses para a cidade. Algumas das galerias principais que foram abertas entre a região da rua de 25 de Março e do Brás são empreendimentos realizados por chineses no mercado imobiliário. Mesmo quando não são proprietários, muitas vezes alugam um espaço e sublocam em vários boxes para locatários majoritariamente chineses. De modo que a migração chinesa e o desenvolvimento do nicho de mercado no qual se concentram têm sido um grande fator de transformação e renovação do espaço urbano, principalmente na 25 de Março e no Brás. 
Galerias comerciais da 25 de Março e do Brás

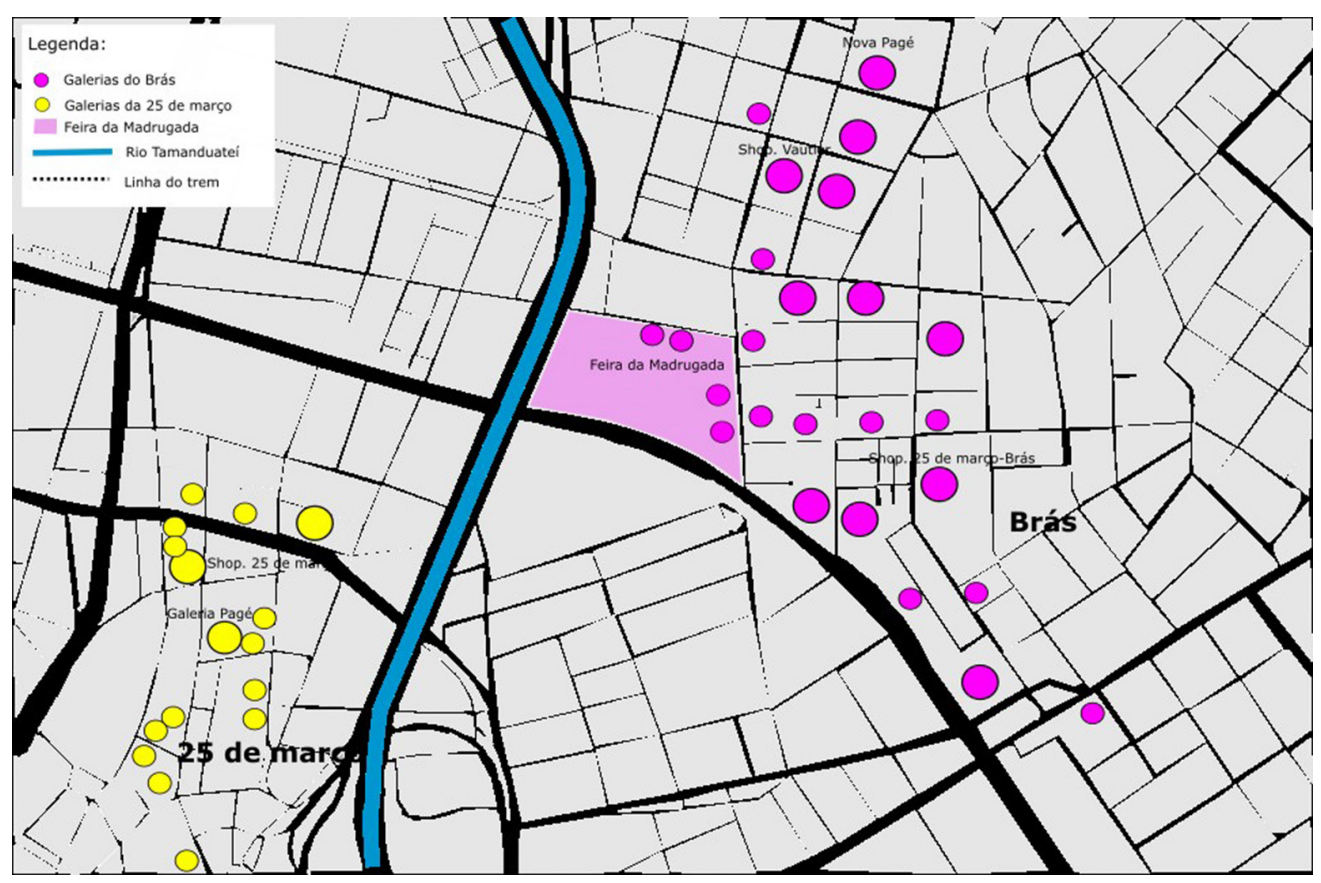

Fonte: Elaboração própria.

A região central da cidade passou por um suposto processo de "degradação" na medida em que viu as elites se deslocarem em direção ao setor sudoeste da cidade a partir dos anos 1970, acompanhando também o deslocamento de serviços, empresas e investimentos públicos. O suposto "abandono" da região central da cidade foi seguido pelo desenvolvimento de serviços e comércio orientados para população de menor poder aquisitivo e grandes concentrações de vendedores ambulantes. De modo que o suposto "abandono" da região central foi acompanhado pela sua popularização já bem marcante na década de 1980 (Villaça, 1998). No caso do Brás, especificamente, constituiu a primeira zona industrial de São Paulo a partir final do século XIX com diversas fábricas instaladas ao lado da linha férrea. Também, a partir da década de 1980, processos de reestruturação produtiva, fechamentos e saídas de fábricas da área deixaram para trás muitos espaços vazios. Nos últimos anos, o desenvolvimento do comércio popular em escala tem alterado 0 espaço urbano. Os galpões industriais anteriormente em desuso agora estão sendo ocupados por galerias; o próprio alargamento da mancha comercial do Brás chegando até o bairro vizinho do Pari segue a difusão das galerias. Um caso emblemático é o da antiga fábrica de biscoitos Tostines que atualmente abriga 
o Shopping Vautier. Também há casos de novos empreendimentos construídos no formato de grandes galerias voltadas a atender às excursões de sacoleiros, com estacionamentos para ônibus, como a Nova Pagé, já no bairro do Pari.

A feira da madrugada, no Brás, que surgiu em 2004 em uma antiga área de manutenção de trens é outro bom exemplo. Aberta todos os dias, exceto aos domingos, das $2 \mathrm{~h}$ da madrugada até as $16 \mathrm{~h}$, desenvolve um comércio atacadista voltado para sacoleiros que chegam à cidade através de excursões de ônibus de diversas regiões do Brasil. Inicialmente foi composta por vendedores ambulantes e pequenos produtores de roupas brasileiros, paraguaios e bolivianos. À medida que foi se valorizando, viu comerciantes chineses comprarem vários pontos de venda, investindo caro, a partir de 2009, e fazendo de alguns pontos na feira uma extensão de suas atividades nas galerias.

A disposição espacial das atividades econômicas e as condições de moradia entre os migrantes chineses não apresentam as mesmas características, mas também chegam a ter impacto no mercado imobiliário voltado para a habitação. Muitos desses migrantes habitam pensões e cortiços manejados por chineses nos próprios distritos da Sé, Liberdade e Aclimação, próximos às áreas onde trabalham no centro; já outros que também atuam nas galerias habitam amplos apartamentos na região da Barra Funda, Perdizes, Paraíso, Bela Vista, Itaim e Morumbi. No bairro da Liberdade, em larga medida caracterizado pela influência da migração japonesa da primeira metade do século XX, a expressiva presença chinesa vai acrescentando outras referências. Alguns anúncios são feitos em chinês por imobiliárias que se concentram nesse público. Lá estão presentes as associações dos migrantes chineses, bem como vários outros serviços de chineses para chineses que possibilitam aos migrantes viverem na cidade sem maiores dificuldades com a língua, pois podem conseguir quase tudo de que necessitam junto a seus compatriotas.

Apesar da influência chinesa na dinâmica urbana da região central que faz com que a expressão "25街" (er shi wu jie) seja vista como sinônimo dessa migração no Brasil, é necessário, de partida, dizer que não se trata da ideia de um "enclave étnico" do tipo Chinatown, como analisado em outros contextos de migração chinesa, em Nova York e São Francisco nos EUA (Zhou, 1992). A dinâmica urbana relativa à migração chinesa em São Paulo tem características históricas e urbanas muito distintas dos casos americanos. ${ }^{4}$ Não é possível restringir essa dinâmica em curso a um "nicho étnico" que coincida com a origem nacional de um grupo específico de migrantes - pois esses centros de comércio são lugares de muita diversidade e articulam diferentes dinâmicas migratórias na cidade - nem tomar apenas a origem como fator determinante para as atividades nas quais os migrantes venham a se concentrar. Migrantes de muitas outras origens também se expressam nesses espaços atualmente.

A região comercial da 25 de Março, desde seus primórdios no final do século XIX, foi constituída pela atividade de migrantes, principalmente sírios e libaneses e, em menor medida, armênios, que a partir das lojas de armarinho notabilizaram a 25 de Março como uma das mais famosas áreas de comércio do País. Sobretudo libaneses forneciam produtos das indústrias têxteis e de confecção local a crédito para "primos" e "compadres" 
compatriotas que, por sua vez, atuando como mascates, percorriam toda a região sudeste distribuindo mercadorias (Truzzi, 1992). Ainda hoje são proprietários de muitos imóveis na região, e o comércio continua a abrigar outros migrantes árabes que chegam atualmente através das redes de acolhida, com destaque para os refugiados da Síria. 0 Brás, em particular, é muito ligado à indústria local de vestuário, na qual atuam muitos migrantes coreanos, bolivianos, paraguaios e brasileiros. Atualmente é o bairro em que a presença chinesa mais cresce e, talvez, esta já seja maior do que na 25 de Março.

Lado a lado com chineses, por vezes dividindo o mesmo balcão, há, portanto, migrantes libaneses, sírios, peruanos, bolivianos, paraguaios, brasileiros, entre outros, também realizando a distribuição de mercadorias made in China ou de artigos produzidos no país. É necessário pensar a dinâmica mais ampla das relações de mercado aqui presentes, não restritas apenas a grupos segundo suas origens nacionais para buscar compreender a diversidade de circuitos migratórios que a região articula. Além disso, a ideia de nicho étnico pode sugerir uma uniformidade entre os próprios migrantes chineses que não condiz com a diversidade de situações em que se encontram nesses agenciamentos comerciais, seja pelas temporalidades dos diferentes fluxos migratórios provenientes da China, seja pelas diferenças das províncias de origem que acompanham essas temporalidades e, em alguma medida, a própria posição que ocupam na dinâmica mais ampla de comércio nas galerias. Essa diversidade existente entre os migrantes é fundamental para compreender como se deu sua concentração nesse nicho de mercado em São Paulo.

\section{Temporalidades dos fluxos migratórios}

A migração chinesa para o Brasil tem mais de 200 anos. Conforme a literatura indica, o primeiro grupo de que se tem registro teria desembarcado no País em 1812, na cidade do Rio de Janeiro, para trabalhar nas plantações de chá (Leite, 1999; Dantas, 2006; Verás, 2008, Chang-Sheng, 2009; Weinong, 2012). Weinong (ibid.) distingue quatro fases da migração chinesa para o Brasil. Na Tabela abaixo reproduzimos alguns dados extraídos de seu texto como principais origens de cada período e estimativas aproximadas, ${ }^{5}$ e nela acrescentei a estimativa da Associação Chinesa do Brasil em 2012.

0 primeiro ciclo da migração chinesa para o Brasil, cujos registros iniciais são de 1812, representando os primeiros asiáticos a se estabelecerem no País, esteve ligado a uma tentativa de introdução do cultivo do chá no Rio de Janeiro, tendo em vista o abastecimento do mercado inglês (Leite, 1999; Lesser, 2001; Dantas, 2006; Chang-Sheng, 2009). Porém, 0 cultivo não deu certo por conta do clima muito quente. Depois, na segunda metade do século XIX, quando começa a tomar força o movimento pelo fim da escravidão em um momento em que a formação nacional brasileira estava em pleno debate, a introdução em massa dos trabalhadores chineses, através do sistema coolie, chegou a ser cogitada. Mas não prosperou pelas questões racistas que influenciavam o debate sobre a formação do Brasil como nação no período (Leite, 1999; Lesser, 2001; Dantas, 2006). No entanto, como destaca José Leite (1999), ainda assim a influência chinesa era notável. ${ }^{6}$ 


\section{Ciclos da migração chinesa para o Brasil}

\begin{tabular}{|c|l|c|}
\hline \multicolumn{1}{|c|}{ Períodos } & \multicolumn{1}{|c|}{ Origens } & Ano e estimativa \\
\hline $1812-1900$ & Guangdong - Macau & $1812-1.410$ pessoas \\
& & $1881-2.000$ pessoas \\
\hline $1910-1949$ & Zhejiang (Qingtian) & $1931-820$ pessoas \\
& & $1949-1.000$ pessoas \\
\hline \multirow{2}{*}{$1950-1979$} & Taiwan e países do sudoeste asiático & $1959-6.748$ pessoas \\
& & $1967-17.490$ pessoas \\
& & $1972-40.000$ pessoas \\
\hline \multirow{2}{*}{$1980-2016$} & Guangdong, Zhejiang, Fujiang, Shanghai, & $1984-70.000$ pessoas \\
& Jiangsu, Shandong, Anhui, Shanghai, Jiangxi & $1988-100.000$ pessoas \\
& & $2012-250.000$ pessoas* \\
\hline
\end{tabular}

Fonte: Weinong (2012, p. 6).

*Baseado em estimativa da Associação Chinesa do Brasil.

Com efeito, ao longo de quatro séculos do segundo terço do século XVI até pelo menos o segundo quarto do século XIX (quando o país de repente e quase à força se converte ao Ocidente, afrancesando-se e se inglesando da noite para o dia, arrependido de ter permanecido por tanto tempo índio, africano e asiático e envergonhado de ter sido se não na epiderme mentalmente vermelho, negro e amarelo antes de ser branco) -, ponderável influência chinesa atingiu o Brasil, assumindo entre nós formas específicas e conotações inconfundíveis, que se traduziam no devido tempo nos hábitos, modos de viver e fazer que mesmo hoje longe estão de se terem esgotado, fundamente arraigados como se acham na alma nacional. (pp. 12-13)

0 Brasil era essencialmente um País rural a época, e, apesar do pequeno número, os chineses se faziam notáveis em alguns centros urbanos, principalmente no Rio de Janeiro.
0 segundo ciclo, mais discreto, seria marcado por migrantes da cidade de Qingtian, província de Zhejiang, que teriam se instalado no Rio de Janeiro a partir de 1910. Porém, até hoje, a migração a partir da pequena Qingtian situada em uma região montanhosa da província tem uma relação com São Paulo e Rio de Janeiro. Trata-se de uma dinâmica peculiar em relação à maior referência sobre a migração chinesa baseada nos cantoneses, província de Guangdong. No começo do século XX, os qingtianeses teriam estabelecido uma dinâmica migratória para a Europa para trabalhar na indústria têxtil. Os primeiros nesse período que chegaram ao Rio de Janeiro teriam passado por uma experiência migratória anterior na França (Guo, 2005). No princípio, eles atuavam como sacoleiros e ambulantes até depois estabelecerem lojas que vendiam toalhas bordadas, porcelanas e lenços de seda, já nessa época importados da China. Alguns poucos também se 
estabeleceram em São Paulo a partir da década de 1930 (Weinong, 2012; Chang-Sheng, 2009; Guo, 2005).

Porém, a dinâmica em questão neste artigo se concentra em uma parte do terceiro e quarto períodos, sobretudo a partir dos anos 1970. Como vimos, a saída da China Continental entre 1949 a 1979 era muito restrita, de modo que nesse momento os migrantes chineses que chegavam ao Brasil ou eram de Taiwan ou passavam por lá antes de conseguirem chegar; outras opções seriam Hong Kong e Macau. Alguns dos primeiros taiwaneses que chegaram ao Brasil nesse ciclo vieram com o auxílio de entidades religiosas cristãs, entre eles um grupo que fundaria em São Paulo a Primeira Igreja Presbiteriana de Formosa do Brasil, situada no bairro da Liberdade. Por conta das tensões políticas e dos conflitos existentes nesse período, a migração chinesa para o Brasil teve um incremento substancial nas décadas de 1960 e 1970, como podemos notar refletido nas estimativas da Tabela acima, com um rápido crescimento em curto intervalo de tempo. Os migrantes procuravam refúgio das tensões políticas que envolviam Taiwan e traziam recursos que foram investidos no seu estabelecimento no País, agora principalmente na cidade de São Paulo. Investiram em mercearias, restaurantes e pastelarias, estabelecimentos nos quais empregavam compatriotas, e alguns também se tornariam profissionais liberais. Nessa época, taiwaneses e coreanos constituíam o principal grupo de migrantes transnacionais para o Brasil. 0 governo brasileiro chegou a restringir a emissão de vistos impedindo que os migrantes chegassem de maneira regular. Uma alternativa adotada por alguns chineses que procuravam se reunir com familiares e parentes em São
Paulo era viajar para o Paraguai e, de lá, atravessar a fronteira entre Ciudad del Este e Foz do Iguaçu sem a documentação exigida. ${ }^{7}$

Além disso, a partir do reconhecimento do governo de China Continental pela ONU, em 1971, e da posterior visita do presidente americano Richard Nixon à China Continental, deu-se início a um momento difícil para os taiwaneses que temiam que a ilha fosse invadida pelo continente, o que fez aumentar o fluxo de migrantes para o Brasil. No plano diplomático, depois da revolução comunista, o Brasil havia rompido relações com Pequim e passado a reconhecer o governo de Taiwan como representante da China a partir de 1952. Essa situação perdurou até 1974 quando o governo brasileiro, seguindo as resoluções da $\mathrm{ONU}$, reestabeleceu a diplomacia com a República Popular da China e, em consequência de exigência do governo chinês de Pequim, rompeu vínculo com a República da China, governo de Taiwan (Biato Jr., 2010).

Ao mesmo tempo, o governo paraguaio, desde 1957, reconhece a autonomia de Taiwan, enquanto Estado independente, e é um dos poucos países que não mantêm relações diplomáticas com o governo da China Continental ainda hoje. Essas diferenças exerceram grande peso na orientação e posterior alteração dos fluxos migratórios de chineses entre Brasil e Paraguai que, ao mesmo tempo que os diferenciavam, também criavam uma relação entre eles. 0 governo do Paraguai estabeleceu um "regime especial de importação" em Ciudad del Este, espécie de zona franca que criava incentivos para o comércio de bens importados (Rabossi, 2012). Enquanto isso, no Brasil, devido à crise do petróleo nos anos 1970, que gerou grande evasão de divisas, o governo passou a sobretaxar a importação de todos os 
bens supérfluos. Tal situação gerava uma grande diferença de preços entre os dois lados da fronteira e também oportunidades para quem estivesse disposto a correr o risco de trazer as mercadorias. Nessa ocasião, muitos chineses e libaneses estabeleceram empresas de importação em Ciudad del Este. ${ }^{8}$ Enquanto por lá eles contavam com incentivos fiscais e as relações diplomáticas entre Taiwan e Paraguai favoreciam o comércio exterior e a predominância dos taiwaneses (Pinheiro-Machado, 2010), em São Paulo estavam justamente em um contexto de restrição às importações. Na origem dos circuitos comerciais que ligam os mercados populares do centro de São Paulo à China, passando por Ciudad del Este, havia uma interconexão com chineses e libaneses que se estabeleceram no Paraguai. As importações eram realizadas a partir do país vizinho, e teria sido em meados dos anos 1970 que os primeiros migrantes chineses se instalaram em galerias comerciais da rua 25 de Março, trabalhando na distribuição dos artigos importadas, a princípio, a partir de Miami, Taiwan ou Hong Kong que chegavam via Paraguai.

A partir dos anos 1980, popularizou-se no Brasil a atividade dos sacoleiros que realizavam excursões frequentes à Ciudad del Leste para se abastecer de mercadorias e revendê-las sobretudo no comércio ambulante. De modo que a rota China-Paraguai-Brasil constituiu um elemento importante para milhares de pessoas que trabalhavam informalmente, bem como para o consumo das mercadorias made in China colocadas em circulação por essa dinâmica (Pinheiro-Machado, 2008; 2009). Gradativamente, a partir de meados dos anos $1990 \mathrm{e}$ ao longo dos anos 2000, essas configurações vão se alterando. As restrições às importações no Brasil que conferiam vantagem ao contrabando com o Paraguai vão se esvanecendo por conta da abertura econômica brasileira, a partir de 1992, e também dos acordos comerciais do Mercosul, entre outros fatores, de modo que muitas "feiras do Paraguai", como ainda são apelidados alguns centros de comércio popular, são, de fato, abastecidas por São Paulo atualmente (Rabossi, 2012). Empresas de importação e exportação passaram a operar no centro de São Paulo, realizando negócios diretamente com a China. As mercadorias que já eram negociadas principalmente a partir da cidade de Guangzhou, na província de Guangdong, passaram posteriormente, também a serem negociadas do mercado atacadista de Yiwu, na província de Zhejiang.

Houve casos de migrantes chineses que deixaram a cidade fronteiriça de Foz do Iguaçu para se estabelecerem na capital paulista. A partir desse período, a migração a partir de Guangdong também se fortaleceu, assim como as províncias de Zhejiang e Fujian. Ao que foi possível levantar junto aos chineses nas galerias, mas também pelas associações de chineses existentes em São Paulo, muitos viriam especialmente das cidades de Wenzhou e Qingtian e, em menor medida, de Putian e Jiangmen. Em algumas galerias da 25 de Março e do Brás, são faladas até quatro línguas ou dialetos chineses diferentes: mandarim, cantonês, wenzhounes e qingtianês. Acompanhando parentes, amigos e conhecidos que já se encontram no País, ou apenas seguindo notícias e informações que tratam das oportunidades do comércio em São Paulo, muitos jovens viajaram para se tornarem locatários e distribuidores de mercadorias de seus compatriotas já bem estabelecidos na cidade. São poucos os que 
realizam o comércio transnacional comparativamente aos que distribuem as mercadorias. Desse modo, a relação entre os estabelecidos e os recém-chegados parece algo decisivo na dinâmica das galerias.

A pesquisa de Piza (2012) desenvolveu a hipótese de uma divisão do trabalho entre as gerações dos migrantes chineses no dispositivo comercial das galerias. Segundo esse autor, o protagonismo dos migrantes da primeira geração (1950 a 1960) seria um fator propulsor para a migração massiva mais recente. Seriam eles que teriam a "condição transnacional", nas palavras do autor, que permitiria abrirem empresas e realizarem o trânsito de mercadorias com o outro lado do globo (ibid., p. 19). Assim, como donos das importadoras, os migrantes chineses da primeira geração seriam também os controladores das principais galerias. De modo que Piza aponta para a multiplicação de atores no dispositivo das galerias e as "clivagens internas, hierarquias, conflitos e solidariedades" entre eles (ibid., pp. 88-89).

Atualmente, mesmo alguns migrantes que chegaram depois da década de 2000 também atuam na importação, que se tornou algo bem mais simples nos últimos anos. Os diversos tipos de relações de crédito que se desenvolvem entre os chineses no interior das galerias também parecem ter sido um fator propulsor para essa dinâmica (Hua-Sheng, 2008; Freire da Silva, 2014). Os mecanismos de financiamento, como consórcios ou o crédito através do fornecimento de mercadorias e das vendas consignadas, podem criar compromissos entre estabelecidos e recém-chegados que facilitam a incorporação de quem chega, por um lado, ao mesmo tempo que expande os negócios de quem já está estabelecido, por outro. Assim vemos muitos boxes, lado a lado, vendendo as mesmas mercadorias. A formação de grupos de crédito rotativo também aparece como estratégia utilizada para investir na aquisição de pontos de comerciais. As relações financeiras desenvolvidas entre os migrantes nas galerias parecem um elemento importante desses agenciamentos.

Weinong (2012) sintetiza o papel desses pequenos pontos de comércio para a migração chinesa no Brasil:

[...] Olhando esses que vão para o Brasil com poucos recursos e sem saber 0 português, a indústria sacoleira pode ser muito bem uma espécie de acumulação primitiva simples e viável para conseguirem juntar dinheiro para abrir uma conta em banco, aprender uma ocupação, como uma forma de entrada mais fácil. Naturalmente esse é só o primeiro passo, o melhor é ser distribuidor atacadista e fazer a conexão com a produção na terra natal, fazer um grupo de crédito para comprar mais e em melhores condições para depois vender barato, conseguir revender rapidamente e juntar fundos para a autossuficiência da família. [...] Não é difícil imaginar que a absoluta maioria dos sacoleiros chineses vê a atividade apenas como um trampolim. Fazer muitos clientes, ter uma ideia do português, familiarizar-se com seu modo de ser e acumular recursos até avançar para novas iniciativas, primeiro um pequeno negócio de coisas variadas, lojinhas de artigos de presente e papelaria, roupas, brinquedos e acessórios, relógios, joias e afins. Quando as circunstâncias permitirem, subir 0 nível e partir para o atacado, supermercados, empresas de importação e exportação, assim como outros ramos de atividade. (p. 6 - tradução livre) 


\section{Qiaowu: a política de migração e as associações chinesas}

A formação das associações foi importante para o desenvolvimento desses circuitos, assim como as câmaras de comércio. Elas constituem canais de informação sobre ambos os lados que são fundamentais para a circulação de pessoas e mercadorias entre São Paulo e a região sul da China. Como destaca Xiang (2007), um novo regime de mobilidades teria se estabelecido na China pós-reformas. Tal mudança teria ocorrido tanto interna quanto externamente, com o aumento de migração entre as províncias, principalmente em direção às grandes cidades próximas à costa e também à saída para o exterior, sobretudo a partir de algumas províncias que já tinham um histórico de mobilidade transnacional, como Guangdong, Zhejiang e Futian. Houve um crescimento substancial da migração chinesa justamente a partir do período pós-abertura e reformas de mercado. Como Xiang argumenta, não foi apenas a possibilidade de migrar que mudou, também houve uma política ativa do governo chinês, através do Overseas Chinese Affairs Office, de estabelecer contato com os migrantes no exterior, em um primeiro momento com o incentivo a retornos diretos para investir na terra natal, depois através de projetos colaborativos que atenuariam as distinções entre os retornados e aqueles no exterior, em que a prosperidade do povo chinês fora da China seria vista como a prosperidade da própria China.

0 estímulo à formação das associações seria um aspecto dessa política de aproximação e manutenção de contato com os chineses no exterior. Como aponta Weinong (2012, p. 15), os principais objetivos da atuação das associações no Brasil seriam unir os compatriotas, "contribuir para promover seus interesses e o desenvolvimento da sociedade local", auxiliá-los a promover sua imagem, compreender as leis brasileiras e superar as dificuldades. 0 auxílio com a educação chinesa e brasileira também seria uma das bases da atividade das associações, assim como atividades de recreação e promoção cultural.

As associações são responsáveis por promover os "assuntos chineses no exterior" (侨务qiáowù) e estão ligadas ao Overseas Chinese Affairs Office (OCAO). Esse órgão é um ministério ligado diretamente ao Primeiro Ministro do governo Chinês para auxiliá-lo na formulação das políticas chinesas no exterior; teria ainda as funções de informar a situação dos compatriotas no estrangeiro, orientar e promover a economia da China no exterior, promover a imagem da China e auxiliar os migrantes nas suas dificuldades. ${ }^{9} 0$ órgão teria sido criado justamente em 1978, dentro do processo de abertura e da reformulação das relações da China com seus migrantes no exterior. Os representantes das principais associações reúnem-se pelo menos uma vez por ano na China, para informar a situação em cada país. Trata-se de algo mais do que um órgão diplomático porque opera também em um nível "infradiplomático" junto aos migrantes. São canais de informações e redes estruturadas com pontos em diversos países do planeta. Taiwan também tem um órgão similar, o Overseas Community Affairs Council, fundado em 1926 ainda durante o período do governo nacionalista e que se transferiu para a ilha depois da revolução. Desde o princípio, sua função também seria proteger e assistir ao 
desenvolvimento econômico dos compatriotas no exterior.

Assim, as relações associativas e as câmaras de comércio entre os chineses em São Paulo são componentes dessa dinâmica social que articula Brasil e China através da circulação de pessoas e mercadorias; mais do que isto, elas são um ponto forte dessa articulação. Por meio dessas associações, é possível para os governos das províncias chinesas procurarem canais de distribuição junto aos migrantes e, assim, fomentarem as suas economias locais. Como é o caso da cidade de Yiwu, na província de Zhejiang, onde uma empresa estatal controla o maior mercado atacadista de pequenas commodities do mundo e que mantém contato com a Associação Chinesa do Brasil (Freire da Silva, 2014, p. 153).

As associações e as câmaras de comércio são muitas e também floresceram bastante ao longo dos últimos 20 anos. A Associação Chinesa do Brasil é a principal dessas associações, congregando mais de 30 outras associações concentradas principalmente em São Paulo, mas também presentes em outras partes do País. Surgiu no começo dos anos 1980 para fazer um trabalho voltado à orientação dos migrantes que se encontravam em São Paulo em relação à documentação. Quando se estabeleceu a embaixada da China em Brasília em 1974, não existia o consulado em São Paulo, que só foi criado em 1985. A associação prestava o serviço auxiliar. No entanto, mesmo depois de instalado o consulado, a associação continuou desempenhando um papel importante. Para além das orientações relativas à regulação migratória e também aos aspectos de difusão da cultura, as associações oferecem auxílio com as burocracias brasileiras, algumas atuam também na área comercial, são lugares de trocas de informações e canais para oportunidades de negócios de ambos os lados (ibid.). Weinong (2012) analisa, por exemplo, a atuação das associações no auxílio aos chineses durante o processo de anistia migratória em 2009. Assim, apesar da grande presença dos migrantes chineses na cidade, raramente recorrem às entidades que prestam auxílio aos migrantes em São Paulo, pois eles contam com estruturas próprias que prestam esses serviços.

Com o aumento da migração ao longo dos últimos 20 anos, outras associações foram criadas de acordo com as províncias de origem dos migrantes, como a Associação de Guangdong e a Associação de Zhejiang; e mesmo por cidades, com destaque para a Associação de Wenzhou e a Associação de Qingtian. Porém, outras associações já existiam anteriormente, como o Centro Social Chinês de São Paulo, que seria ligada aos taiwaneses. 0 Centro Social Chinês deriva da perda do status do antigo Consulado da República da China, assumindo as funções culturais, enquanto o Escritório de Taipei, no Brasil, responde pelos assuntos consulares de Taiwan na cidade de São Paulo. Tanto o governo de Taiwan como o governo da China pós-abertura estabeleceram políticas de reaproximação com seus migrantes no exterior através do estímulo às associações entre os migrantes, tendo em vista a promoção de sua produção industrial e exportações (Xiang, 2007).

As associações, as câmaras de comércio e os canais de informação, fomentados entre os migrantes como política de governo chinês, têm papel relevante na promoção das relações comerciais entre o Brasil e a China de modo em geral. Para além das associações, também há 
jornais como o Diário Chinês para a América do Sul, com redação e impressão em São Paulo, e o Jornal Chinês da América, nesse caso ligado aos taiwaneses, ambos com sede na Liberdade. Existem ainda os canais de notícias no wechat promovidos pelos próprios migrantes, como 0 canal de notícias da 25 de Março (巴西25街).

Refletindo sobre Qiaowu, como as políticas extraterritoriais de governo para os migrantes chineses no exterior, To (2009) afirma que muitos países têm políticas orientadas para seus migrantes no exterior, mas que todas elas seriam pálidas se comparadas as políticas qiaowu do governo chinês. Essa política representaria uma superestrutura de vários níveis, consistindo de agências e organizações governamentais, diplomáticas e não governamentais que miram uma população de 48 milhões de chineses ao redor do globo (ibid., p. 2). Esse autor analisa que nenhuma outra iniciativa governamental alcançou a escala de operação e sofisticação nem buscou alcançar o nível de sucesso que a China alcançou em uma vasta variedade de programas especializados. $\mathrm{A}$ única experiência que se aproximaria é a do governo de Taiwan através do Overseas Community Affairs Council, que enfatiza exclusivamente os esforços pró-Taiwan.

\section{Entre extorsões, assaltos e a crise econômica}

Os migrantes chineses são "operadores de escala" (Glick-Schiller e Çaglar, 2008; Piza, 2012) para a circulação de produtos "made in China" no comércio popular. Essa dinâmica transnacional deslocou a centralidade desses fluxos de comércios de Ciudad del Este para São Paulo.
Isso não quer dizer que Ciudad del Este não tenha mais lugar no comércio de fronteira com o Brasil, o circuito de sacoleiros para Ciudad del Este permanece em menor escala, além do desenvolvimento de outros centros de comércio de fronteira, como Salto del Guairá. Ainda existem excursões que se dirigem para lá regularmente com pessoas em busca de mercadorias, sobretudo cigarros e artigos eletrônicos. Porém, o fluxo de ônibus que parte atualmente em direção ao Paraguai é bem menor, ao mesmo tempo que o circuito dos sacoleiros se fortaleceu em direção a São Paulo.

0 deslocamento da centralidade na distribuição das mercadorias importadas diretamente da China para São Paulo, sem a triangulação pelo país vizinho, envolve mudanças de mediações para o comércio transnacional, bem como das formas de controle e fiscalização. Diferentemente da informalidade característica do trânsito de mercadorias na fronteira com o Paraguai (Pinheiro-Machado, 2008), há toda uma dimensão formal a partir de empresas de importação e exportação sem a qual não seria possível esse comércio na escala em que ele se desenvolve. Os procedimentos, os trâmites, as obrigações burocráticas e as negociações aqui são bem diferentes das que ocorrem nas passagens através da Ponte da Amizade que liga a fronteira Brasil-Paraguai. 0 trajeto das mercadorias agora parte do desembaraço alfandegário no porto de Santos e do Rio de Janeiro, passando pelos caminhões das transportadoras, descarregamento nos depósitos e, finalmente, chegando à distribuição entre os boxes das galerias.

Em todo esse trajeto, os portadores das mercadorias estão sujeitos à fiscalização e, eventualmente, podem ocorrer situações de 
corrupção e extorsões por parte de fiscais da alfândega, agentes da Receita Federal, policiais civis. Apesar da dimensão formal que envolve esse fluxo, frequentemente há incompatibilidades entre os números declarados e quantidades e valores efetivamente importados ou, então, ausência de notas fiscais que comprovem a origem das mercadorias expostas nos boxes, sonegação fiscal e não recolhimento de tributos devidos, portanto. No porto, a fiscalização mais apurada do conteúdo dos contêineres é realizada por amostragens, mas também são fiscalizados de acordo com o histórico da empresa que faz a importação, dos produtos importados e dos países de origem. Quando uma carga é retida gera uma série de negociações que envolvem agentes alfandegários, importadores, advogados, tradutores e intérpretes para a liberação das cargas. Há casos que envolvem o momento do descarregamento das mercadorias nos depósitos, com ameaças de apreensão já na área central da cidade. Uma vez dentro das galerias, são os boxes que passam a responder pelas mercadorias, estes também a partir de empresas constituídas.

No entanto, o que mais parece afligir os migrantes nessa dinâmica tem sido uma série de assaltos direcionados aos chineses que tomaram força especialmente em 2015. Nas redes sociais utilizadas pelos chineses como wechat e em canais específicos de notícias da 25 de Março, não houve assunto mais comentado do que invasões e roubos a suas residências, bem como arrombamentos e saques em suas lojas. A grande rotatividade monetária propiciada pela atividade comercial, o uso majoritário de dinheiro vivo nas transações e as imagens difundidas de que os chineses costumam guardar grandes somas de valores em espécie em suas casas teriam despertado a atuação de assaltantes e de quadrilhas que parecem se especializar no roubo a chineses. As vítimas mais frequentes certamente constituem aqueles que têm menos recursos para investir em segurança em suas casas e seus boxes, além de parecerem oferecer menor riscos para os assaltantes. Como é muito frequente entre aqueles que estão a menos tempo no País não terem sua situação regularizada, por vezes não fazem boletins de ocorrência sobre os assaltos e não recorrem à polícia por medo e falta de informação.

As queixas são realizadas junto aos canais de notícia dos chineses na cidade, bem como às associações e ao próprio Consulado Geral da China em São Paulo. A evolução das queixas ao longo de 2015 levou as autoridades consulares chinesas a promoverem audiências com representantes da Secretaria de Segurança Pública do Estado de São Paulo, com reuniões entre o Cônsul Geral da China, o secretário de segurança Pública, representantes da polícia militar e o delegado da Delegacia de Investigação sobre Furtos e Roubos a Condomínios e Residências. Dessas reuniões, teriam sido realizados acordos para cooperação nas investigações, bem como uma série de recomendações de segurança para os chineses. Membros de diversas associações também promoveram um Comitê de Segurança para pensar alternativas de redução dos crimes contra chineses na cidade, com a proposta de criar uma plataforma sobre os riscos, dicas de segurança, além de acompanhar os casos de violações contra os direitos dos compatriotas e oferecer auxílio jurídico. A proposta da plataforma vai um pouco 
além das questões de segurança, sugerindo também a criação de auxílio para serviços de contabilidade fiscal, um fundo de caridade para socorrer compatriotas em situação de emergência e um guia para os recém-chegados sobre empregos, cultura, costumes e segurança no Brasil.

De um modo geral, o dinamismo das galerias para a mobilidade migratória dos chineses em São Paulo já apresenta alguns sinais de saturação e, com o início da crise em 2014, até mesmo uma tendência de redução. De fato, a partir do comércio nas galerias, alguns migrantes conseguiram alguma mobilidade ao acumularem recursos e se tornarem donos dos próprios pontos, ao que a pesquisa indica, pelo menos entre aqueles que chegaram até 2012. Estabelecer-se com recursos próprios em bons pontos comerciais parece cada vez mais difícil para os recém-chegados. Nesse sentido, os aluguéis caros pagos nos lugares mais valorizados vêm causando uma tendência à dispersão como alternativa à saturação do centro de São Paulo. Essa tendência de dispersão aponta primeiramente a saída da 25 de Março em direção ao Brás, onde a disponibilidade maior de espaço e de boxes em galerias torna o preço mais baixo. 0 preço caro do aluguel está comprimindo as margens de lucro para o comércio.

Um conflito entre o proprietário de uma galeria na 25 de Março e os seus locatários chamou a atenção em outubro de 2015. 0 conflito ocorreu depois que o proprietário tentou aumentar o aluguel em $40 \%$ do valor. Os locatários recusaram-se a pagar e houve um confronto com os seguranças do proprietário, ficando alguns locatários feridos. 0 caso foi bastante comentado nos canais de notícias do wechat utilizadas pelos chineses em São Paulo. Reclamavam da falta de bom senso do proprietário taiwanês diante de um cenário de queda nas vendas e, principalmente, da alta do dólar que comprometeu bastante a renda no comércio, de como a 25 de Março estava se tornando inviável pelos seus preços e que, por isso, muitos estariam se mudando para o Brás. Um representante da Associação de Qingtian também se manifestou sobre o caso. A maior parte dos comerciantes dessa galeria seria proveniente de Qingtian, e o proprietário seria taiwanês:

Aos olhos da maioria, o senhor proprietário sempre foi considerado como compatriota, embora seja taiwanês. Todo mundo tem orgulho das suas realizações, então, toda vez que abre uma loja a maioria dos inquilinos são quase todos chineses. Acontece que os negócios na 25 de Março já não são tão bons quanto antigamente, claramente tem muita gente se transferindo para o Brás, Pari e outros lugares em busca de meios de subsistência, pois ficar não está fácil. Assim, aumentar em $40 \%$ o aluguel nesse momento não é razoável! Afinal as pessoas viajaram milhares de quilômetros para estar no Brasil. [...] Eu sei que a maioria dos seus clientes são de Qingtian, eu também sou do povo de Qingtian. Os qingtianeses são trabalhadores e valentes, podem ter agido no impulso, mas o segurança não pode fugir das suas responsabilidades. [...] Finalmente, espero que tenha razão e sabedoria para resolver o problema e não deixe isso virar uma grande luta que crie um ambiente irreparável. Há muitas maneiras de resolver o problema sem força, acredito que vai encontrar uma solução sem força. Afinal, não estamos diante de um japonês, certo? (wechat 巴西25街, 10/11/2015; tradução livre) 
0 proprietário acabou revendo a decisão e estabelecendo um acordo com os locatários: desconto de $5 \%$ no valor do aluguel, preços congelados por um ano e prorrogação da luva do ponto em 9 meses (de 24 para 33 meses).

Ainda há poucas informações a respeito, mas, com a saturação do centro de São Paulo, outros centros de comércio popular em outras cidades no interior de São Paulo e estados, como o Shopping Oiapoque em Belo Horizonte e Feira de Caruaru em Pernambuco, parecem se colocar como alternativas para os migrantes chineses que já se encontram no País.

0 aumento do dólar em 2015, no entanto, foi o fator de maior impacto entre os migrantes chineses nas galerias. Como se trata de uma dinâmica comercial transnacional, as transações são calculadas em dólar. Para além da maneira como a alta do dólar afeta o comércio ao deixar seus produtos menos competitivos, o valor do dólar afeta diretamente as dívidas existentes entre os migrantes, de modo que esse elemento também tem se apresentado como fator de conflitos entre os chineses, principalmente para aqueles que chegaram mais recentemente e viram suas dívidas com compatriotas se multiplicarem à medida em que o dólar aumentava. 0 dólar afeta a dinâmica de comércio dos migrantes chineses por várias perspectivas, seja pelos sistemas de crédito em dólar, seja pela importação das mercadorias, seja pelos preços de passagens aéreas e diminuição das vantagens comparativas do preço das moedas para aqueles que enviam parte da renda para a China.

\section{Conclusão}

Uma das principais mudanças que teria ocorrido na China no processo de abertura foi justamente quanto à relação com os chineses que se encontravam no exterior e sobre a própria possibilidade de migrar para outro país. Internamente também foi permitido maior mobilidade entre as províncias. De modo que as relações da China com seus migrantes no exterior têm um papel importante nas dinâmicas que se estabelecem com vários países.

A migração chinesa para o Brasil é marcada por uma grande diversidade de processos e temporalidades distintas; aqui se procurou falar da especificidade desse dinâmica no centro de São Paulo e seu processo de formação. Ela é importante pelo grande número de pessoas que envolve e também pela maneira como tem impactado nas transformações recentes na região da rua 25 de Março e do Brás no centro da cidade. Além disso, estabelece uma ligação muito concreta com alguns lugares específicos em Guangzhou e Yiwu, através de uma circulação constante de pessoas entre China e Brasil. Muitas mercadorias tão presentes em nossa vida material cotidiana são colocadas em circulação a partir da dinâmica que procuramos apresentar neste artigo.

Os circuitos ligados ao comércio nas galerias não ocorrem em universos paralelos aos atores mais capitalizados que procuram menores custos na China. Muitas vezes também é, a partir das câmaras de comércio ligadas aos migrantes chineses, que outras empresas 
brasileiras se aventuram nos mercados chineses em busca de fornecedores. As galerias enquanto dispositivo comercial estão no centro de um agenciamento transnacional que coloca em movimento pessoas e mercadorias e, muito concretamente, circulam entre mercados no centro de São Paulo, principalmente aos mercados das cidades de Guangzhou e Yiwu. Neste artigo, buscou-se apresentar esse circuito dos chineses nas galerias da região central de São Paulo como pontos fortes das conexões Brasil-China.

\section{Carlos Freire da Silva}

Universidade de São Paulo, Faculdade de Filosofia, Letras e Ciências Humanas, Departamento de Sociologia. São Paulo, SP/Brasil. carlosfreire.17@gmail.com

\section{Notas}

(1) As estimativas da Organização Internacional das Migrações (OIM), órgão da ONU, citadas por Wei (2010) eram de 35 milhões de chineses vivendo no exterior em 2005. Estimativas de 2012, do Overseas Chinese Affairs Office, órgão do governo chinês voltado aos migrantes chineses no exterior, dão número de cerca de 50 milhões vivendo no exterior.

(2) http://portal.mj.gov.br/data/Pages/MJA5F550A5ITEMIDF7B2EE1D60D4405F80C9C91D4EA12FC3PTBRNN. $\mathrm{htm}$

(3) Ver: http://www.jusbrasil.com.br/diarios/49904335/dosp-cidade-17-01-2013-pg-56. Esses números são produzidos pela própria estrutura de associações dos migrantes chineses no Brasil. Importante ressaltar que os números incluem também a estimativa dos descendentes (华侨 huáqiáo, nascido na China, 华人 huárén, origem chinesa), de modo que esse recorte amplia o escopo dos migrantes chineses.

(4) Como argumenta Zhou (1992), apesar da existência de outros lugares mundo afora com essa designação, Chinatown foi um resultado das características peculiares da migração chinesa para os Estados Unidos. Ela foi bastante expressiva durante o século XIX, fornecendo mão de obra para a exploração das minas de ouro da Califórnia e para a construção da ferrovia transcontinental. Porém, posteriormente, o governo americano impôs severas restrições aos chineses, proibindo expressamente a migração e a sua participação no mercado de trabalho através do Chinese Exclusion Act, de 1882, que perdurou até a década de 1960. Essas condições teriam sido decisivas para a formação das Chinatown nos Estados Unidos.

(5) Os números são bastante incertos principalmente para as duas primeiras fases.

(6) A pesquisa de Leite apresenta as raízes profundas das influências chinesas no Brasil. Ele pondera que Portugal teria atingido a China pouco depois da descoberta do Brasil, com a circulação da burocracia colonial entre o Brasil, Goa e Macau. Trata da influência da China nos gostos e hábitos arraigados na elite portuguesa e de como isso também se refletiria no Brasil, entreposto nas viagens de ida e volta ao extremo oriente. 
(7) Conforme Choi (1992), o mesmo teria ocorrido com os migrantes coreanos que viajavam para o Paraguai para, posteriormente, tentarem cruzar a fronteira a partir de Ciudad del Este, a fim de procurarem se estabelecer em São Paulo.

(8) Não apenas chineses participaram da formação desse circuito de bens importados. Rabossi (2007) demonstra, por exemplo, a importância da atuação de árabes e muçulmanos no desenvolvimento do mercado de Ciudad del Este e como eles atuaram nos dois sentidos da fronteira a partir de suas casas de importação e exportação, ao introduzirem mercadorias brasileiras no mercado paraguaio e também ao importarem produtos de Miami, Hong Kong, Taiwan e China que depois seriam reexportados para o Brasil.

(9) Ver: http://www.gqb.gov.cn/zyzn/index.shtml.

\section{Referências}

BIATO JUNIOR, O. (2010). A parceria estratégica sino-brasileira: origens e perspectivas (1993-2006). Brasília, Fundação Alexandre de Gusmão.

CHANG-SHENG, S. (2009). Imigrantes e a imigração chinesa no Rio de Janeiro (1910-1990). Leituras da História, v. ano II, pp. 44-53.

CHOI, K. J. (1991). Além do arco-íris: a imigração coreana no Brasil. Dissertação de Mestrado. São Paulo, Universidade de São Paulo.

DANTAS, F. L. (2006). Origens das relações entre o Brasil e a China: a missão especial de 1879. Recife, Liber.

FREIRE DA SILVA, C. (2014). Das calçadas às galerias: mercados populares no centro do Centro de São Paulo. Tese de Doutorado. São Paulo, Universidade de São Paulo.

GLICK-SCHILLER, N. e CAGLAR, A. (2008). Migrant Incorporation and City Scale: Towards a Theory of Locality in Migration Studies. Malmo University, Sweden. Disponível em: <http://dspace.mah.se/ bitstream/handle/2043/5935/WB_2_07_final.pdf>. Acesso em: 2 mar 2016.

GUO, B. (2005). Registro geral dos imigrantes chineses de Qingtian no Brasil (1910-1994). Qingtian, China.

HUA-SHENG, H. (2008). Modelos de financiamento baseados em relações pessoais: experiência de empreendedores chineses no Brasil. Revista de Administração Contemporânea. Curitiba, v. 12, n. 3.

LEITE, J. R. T. (1999). A China no Brasil: influências, marcas, ecos e sobrevivências chinesas. Campinas, Editora Unicamp.

LESSER, J. (2001). A negociação da identidade nacional: imigrantes, minorias e a luta pela etnicidade no Brasil. São Paulo, Editora Unesp. 
PINHEIRO-MACHADO, R. (2008). China-Paraguai-Brasil: uma rota para pensar a economia informal. Revista Brasileira de Ciências Sociais, v. 23, n. 67, pp. 117-133.

(2009). Made in China: produção e circulação de mercadorias no circuito China-ParaguaiBrasil. Tese de Doutorado. Porto Alegre, Universidade Federal do Rio Grande do Sul.

(2010). Uma ou duas Chinas? A “questão de Taiwan” sob o ponto de vista de uma comunidade chinesa ultramar (Ciudad del Este, Paraguai). Civitas. Porto Alegre, v. 10, n. 3, pp. 468-489.

PIZA, D. T. (2012). Um pouco da mundialização contada a partir da região da rua 25 de Março: migrantes chineses e comércio “informal”. Dissertação de Mestrado. São Paulo, Universidade de São Paulo.

RABOSSI, F. (2007). "Árabes e muçulmanos em Foz do Iguaçu e Ciudad del Este: notas para uma reinterpretação”. In: SEYFERTH, G; PÓVOA, H; ZANINI, M.C. e SANTOS, M. (orgs.). Mundos em movimento: ensaios sobre migrações. Santa Maria, Editora da Universidade Federal de Santa Maria.

(2012). "Ciudad del Este and Brasilian circuits of commercial distribution". In: MATHEWS, G.; RIBEIRO, G. L. e VEGA, C. A. (eds.). Globalization from Below: The world's other economy. Nova York, Routledge.

SILVA, M. A. (2008). Guanxi nos trópicos: um estudo sobre a diáspora chinesa em Pernambuco. Dissertação de Mestrado. Recife, Universidade Federal de Pernambuco.

STENBERG, J. (2012). The chinese of São Paulo: a case study. Journal of Chinese Overseas. Singapura, v. 8 , n. 1 , pp. $105-122$.

TO, J. J. H. (2009). Hand-in-hand, heart-to-heart: qiaowu and the overseas chinese. Phd thesis. Nova Zelândia, University of Canterbury.

TRUZZI, O. (1992). De mascates a doutores: sírios e libaneses em São Paulo. São Paulo, Idesp/Sumaré.

VERÁS, D. B. (2008). As diásporas chinesas e o Brasil: a comunidade sino-brasileira em São Paulo. Tese de Doutorado. São Paulo, Pontifícia Universidade Católica de São Paulo.

VILLAÇA, F. (1998). O espaço intra-urbano no Brasil. São Paulo, Nobel.

WEI, S. (2010). China in the global migration order: historical perspectives and new trends. Asia Europe Journal, vol. 8 , issue 1 , pp. 25-43

WEINONG, G (2012). 拉丁美洲华侨华人移民史、社团与文化活动远眺（上册）。广州暨南大学 出版社. (História da migração chinesa na América Latina: associações comunitárias e atividades culturais - v. 1- tradução livre)

XIANG, B. (2007). A new mobility regime in the making: what does a mobile China mean to the world? Idées pour le débat. Paris, n. 10, pp. 1-19.

ZHOU, M. (1992). Chinatown: the socioeconomic potential of an urban enclave. Filadélfia, Temple University Press. 
